\title{
Effects of advanced organizers on attainment and retention of students' concept of gravity in Nigeria
}

\author{
Atomatofa, Rachel $\$ \\ Delta State College of Physical Education, Mosogar,Delta State, Nigeria (atomatofa.ro@gmail.com)
}

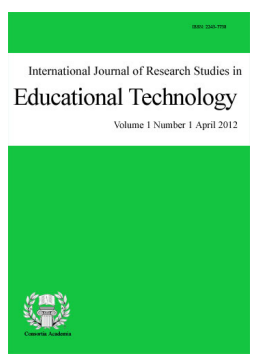

ISSN: $2243-7738$ Online ISSN: 2243-7746

OPEN ACCESS

\section{Abstract}

This study on the effects of advanced organizers on attainment and retention of students' concept of gravity in Nigeria was carried out to find out the efficacy of using advanced organizers to teach students the concepts of gravitation, weightlessness and space travels which are topics the students of junior secondary one have not been previously taught. 80 junior secondary one students from two secondary schools in Delta state Nigeria were used for the study. The students were grouped into two; the advanced-organizer and control group. The exercise took place in six weeks. The advanced organizers were given before each of the four lessons to those in the experimental groups while those in the control had no organizers; they were only taught lessons same with the students in the experimental groups. The dependent variables are the students' attainment and students' retention of the concept of gravity while the independent variable are the advanced organizers. Two research hypotheses and two research questions were stated. Using simple descriptive statistics and t-test statistical analysis the two hypotheses were rejected because there were significant differences in the attainment and retention of concepts of gravity by students in favor of the advanced organizer group. Based on the results educational implications and conclusions were stated.

Keywords: advanced-organizers; instructional-methods; scientific-concepts; previous-knowledge; meaningful learning; rote-memorization 


\section{Effects of advanced organizers on attainment and retention of students' concept of gravity in Nigeria}

\section{Introduction}

The purpose of Education is to learn and learning involves acquiring knowledge which should be retained. Retaining the acquired knowledge and using it to perform a task is what is most important about learning. The method of teaching a particular subject can affect achievement and retention ability of students. This is why a teacher must select good teaching strategies that bring out the essence of the lesson. Results of the junior secondary school students in recent times have shown that the performances of students are very poor in integrated science now known as Basic science and results of different studies have shown that teaching methods is one factor responsible for the high failure rate (Atomatofa, 2007). Researchers have emphasized that the purpose of a good teaching strategy is to create specific learning experience that brings about criterion performances not only for the purpose of test but for change in behavior outside the class (Akeji, 2001; Kayode, 1997; Nneji, 1997; Umudhe, 1998; Yewande, 2000). Therefore, there have been strives over the best teaching methods to use to enable students gain understanding of scientific concepts, knowing that faulty instructional methods kills motivation (Umudhe, 1998). Most science students especially in the lower levels of secondary school see science as abstract and do not seem to clearly understand scientific concepts. They come to class with concepts that are sometimes wrong and there is need for the science teachers to introduce aids like organizers before the lesson to serve as anchors and help in correcting such pre-concepts or alternative concepts.

\subsection{Statement of the Problem}

The problem of science teachers trying to get students to clearly understand scientific concepts has bothered most science educators. The use of Advanced Organizers has been argued by researchers to link previous knowledge with the new learning. Some researchers believe that the gap between prior knowledge and new learning can be closed and students are able to understand better and retain more when organizers are used. The use of Advanced-Organizers is not a teaching method on its own but a teaching strategy needed to help clarify the science concepts the students are trying to attain. Studies have revealed that Advance Organizers favors higher achievement and retention abilities and facilitates acquisition of more scientific concepts.

The study came up because the researcher saw a gap existing in students' attainment of unfamiliar scientific concepts in spite of good teaching methods employed. Students are still having difficulties in understanding of these unfamiliar concepts hence they resort to rote memorization to ensure they pass their science examinations. Rote memorization is not meaningful learning; hence the researcher advocates the use of advanced-organizers besides good classroom learning. Since there are still contrary results of findings in the use or none use of organizers, the purpose of this study was to find out if the use or none use of advanced organizers had any facilitative effect on junior secondary one students' attainment and retention of the concepts of gravity and weightlessness in Delta central senatorial district of Delta state, Nigeria. Based on the problem stated, the significance of the study is as stated below.

\subsection{Significance and limitations of the study}

The study is significant to provide teachers with information on how to redirect their teaching of unfamiliar or new scientific concepts to science students by using teaching methods along with advance organizers that will facilitate and enhance the students' understanding and retention of scientific concepts. The study is also meant to create awareness to science teachers that the introduction and use of advance organizers relevant to the topic gravitation and weightlessness will help prevent students from rote memorization. Gravitation and weightlessness are topics introduced for the first time in the junior secondary one of the new basic science 
curriculum and the use of advanced organizers such as those used in this study may be of help to the students in acquisition of the scientific concepts the teacher wants them to learn. The study is limited to eighty students from two different schools in Warri, Delta state, Nigeria. It was also limited to the use of 4 different advanced organizers, one for each of the four units of lessons.

\subsection{Research questions and hypotheses}

\section{Questions}

a. Will there be any difference in the attainment of the concept of gravity among subjects exposed to advance-organizers and those not exposed to organizer?

b. Will there be any difference in the delayed retention of the concept of gravity among subjects exposed to Advanced-organizers and those not exposed to organizer?

Hypotheses

a. There is no significant difference in the attainment of the concept of gravity among subjects exposed to advance-organizers and those not exposed to organizer.

b. There is no significant difference in the delayed retention of the concept of gravity among subjects exposed to advance-organizers and those not exposed to organizer.

\section{Literature review}

This study is based on the Ausubellian theory of advanced-organizers propounded by David Ausubel. The theory of advanced organizer focuses on meaningful verbal learning. This theory emphasizes and contributes to the aspects of cognitive learning that encourages rapid learning and retention abilities. According to Ausubel (1978), the existing structure of the learners' knowledge at the time of learning is very important before introducing concepts to be learned. When new concepts are related to any of the information already existing in the learners cognitive structure then appropriate learning can take place. Meaningful learning and retention occurs when there is an interaction between previously obtained knowledge and new knowledge. Therefore where no previous knowledge exists what occurs is referred to as rote learning. Another thing that occurs in the absence of relevant anchorage for new learning to take place in students is forgetting. Forgetting occurs because certain details gets integrated but then lose their individual identity. In the absence of previous knowledge Ausubel advocated for advanced-organizers to bridge the gap between new material and existing related ideas. In preparing for advanced organizers and to ensure effectiveness of the teaching, Ausubel states two conditions

$>$ The students must process and understand the information presented in the organizer.

$>\quad$ The organizer must indicate the relationship among the basic concepts and terms that will be used in the topic to be learned. (Woolfolk, Winne, Perry, \& Shapka, 2010).

Students are able to build more complex cognitive structures and deepen their understanding and retention of scientific concepts when teachers help them link old knowledge with new ones by giving students Advance Organizers (AO) in addition to text materials and the lesson itself. The existence of relevant anchoring ideas in the cognitive structures is the primary pre-requisite for subsequent meaningful learning. Ausubel (1978), emphasized that in order to ensure relevant anchoring of learners' ideas, advanced organizers should be given to students. Ausubel (1968) and Allen (1970) earlier supported the use of Advanced Organizers; the advantages among others include providing anchorage or links and avoidance of rote memorization by students. Mayer (1979) further explains Ausubel's theory in terms of his assimilation encoding theory. He emphasized that if the learner already has previous knowledge of the content to be learnt, the AO would not be as effective as when the student is new to the content material. Hence AO is effective for new learning. Results of several studies have 
revealed the efficacy of using advance organizers in teaching students. It is very easy for teachers to learn how to use advance organizers in their classrooms with minimal training, and is easy for students to show interest in using advance organizers.

Advanced Organizers are tools or mental learning aids that help students integrate new information with their existing Knowledge. They are devices that activate relevant schemes or conceptual learning patterns to enable new information more readily subsumed into the learners existing cognitive structures. Teachers are to start with a "Big picture" of the oncoming content (Ausubel, 2000). Advanced-organizers take different forms such as cards, maps, descriptions plus pictures, flowcharts, story maps, Venn-diagrams and questions (Lins \& Chen, 2006); Orals and visuals (Ginthers, 2002); and graphical representations (Herron, Harley, \& Cole, 1995). Both the question and advanced organizers will be used in this study.

Research findings revealed that when teachers focus their advance organizers on content that is most important and not what they think will be most interesting to students, the students always do better (Kulkowich \& Schulz, 1994; Risner, Nicholson, \& Webb, 1994; Redfield \& Rousseau, 1981). Studies carried out by Lin and Chen (2006) and Adejumo (1992) revealed that Advanced-organizers were of facilitative effects on student achievement than the No-Advanced-Organizer group. However there are still controversies on the effects of advanced organizers on achievement and retention of scientific concepts. Some researchers found out that there were no effect of advanced organizers on students' achievement and retention of scientific concepts (Laoye, 1992; Salmon, 2000).

A close look at the present 9-year Basic Education Curriculum in Nigeria reveals that there are four (4) themes in Basic Science Curriculum from Basic 1-9. The lower and Middle Basic Curriculum is primary 1-3 and primary 4-6 respectively and both lower and upper Basics Science Curriculum have a different theme 3 from upper Basic Curriculum which runs from Junior Secondary 1-3. See the Table below:

\section{Table 1}

Basic Science Curriculum Structure

\begin{tabular}{clll}
\hline Themes & Lower basic (Primary 1-3) & Middle basic (Primary 4-6) & Upper basic (Junior secondary 1-3) \\
\hline 1 & You and Environment & You and Environment & You and Environment \\
2 & Non Living things & Living things & Living things \\
3 & You and Technology & You and Technology & Science and Development \\
4 & You and Energy & You and Energy & You and Energy \\
\hline
\end{tabular}

Source: NERDC 2008: 9 -year Basic Education Curriculum

Theme 3 (science and development) in Upper Basic (junior secondary 1-3) is entirely new to the previous classes and one of the topics in this theme is gravitation and weightlessness. The students have not previously learnt contents related to this topic in their previous classes. Therefore will using Advanced Organizers serve as prior knowledge to students or as aid to retention of learnt science concepts? Based on this the researcher intends to find out the effects of using Advanced Organizers to teach Junior Secondary one students the topics Gravitation and Weightlessness in Delta state, Nigeria. Studies carried out by Mohammed (1991), Akinyemi (1992), Ajaja (2006), and Ojeifo (2000) revealed that the use of advanced organizers by students had facilitating effects on the students learning and retention of the concepts they were taught. Mohammed (1991) found out that the students in different classes performed better with the use of organizers in addition to the lessons. However other researchers (Laoye, 1992; Salmon, 2000) in separate researches found out that the use of organizers did not have any facilitative effect on students achievement and retention of the concepts they were taught. These researches show that there are still conflicting results of findings in the use of organizers. 


\section{Methods}

The pre-test, posttest control group quasi-experimental design (Best, 1981) was adopted for this study. The independent variable is the advanced organizers while the dependent variable is the student achievement. Two instructional groups (advance-organizers and No-organizer) and repeated testing (pretest, posttest and delayed retention test).The design employed 2 intact classes randomly selected from different locations across Delta State.

The design is represented diagrammatically as seen below:
E -
$\begin{array}{llll}\mathrm{O} 1 & \mathrm{X} 1 & \mathrm{O} 2 & \mathrm{O} 3\end{array}$
C - O1
$\mathrm{O} 2 \quad \mathrm{O} 3$

Where E1 represents experimental groups 1, C represents control group. O1, O2, and O3 represents pretest, posttest and delayed retention test respectively and they are the same for E1 and C. X1 represents advance organizer treatment for E1 represents No-organizer or no treatment for the control group. The experiment took place within a period of 8 weeks. Week one was for pre-test; weeks 2-5, for the study; week 6, for post-test and week 8 ( 2 weeks after post-test), for the delayed retention test. The researcher ensured that the instruments were not tempered with or given to students beforehand. The two groups were not in the same school. The students in each of the groups had no idea there was another group. Only public schools were used since they consist of vast majority of average students.

\subsection{Participants and process}

The population for the study includes all Junior Secondary one students in all the public secondary schools in Delta central senatorial district of Delta state Nigeria, who study Basic science subjects. Information from the Post-Primary Education Board (PPEB, 2008), shows that the student population for the junior secondary one is 51,120 from the 178 junior secondary schools across Delta central senatorial district of the State. Basic Science is a core subject in the 9-year Basic Education Curriculum. It replaces Integrated Science and so every student in the junior secondary offers the subjects. A sample of 80 students was drawn from the population. Two intact classes from two secondary schools in the Delta central senatorial district of the state were used. Each of the schools was from a different local government area. The procedure adopted was to ensure all the secondary schools used had a Basic science teacher with at least an NCE plus 5 years' experience or a B.Sc. with minimum of 2 years' experience. The schools were those that have started using the new basic science curriculum since the chosen topics were from the new curriculum. The schools were those that had offered students for the JSCE examination for the past 10years.

\subsection{Instrument for data collection}

The instruments used for this study includes:

a. Content materials (CM) consisting of the science concepts: Gravitation and weightlessness, Space travel and Satellites.

b. The Organizers consisting of: Advanced-organizers for the experimental group.

c. The Test packages consisting of: Test of Concept of Gravity (TCG) used for pretest and scrambled for post and delayed retention tests respectively.

The content materials consisting of 4 units were taken from the Basic Science Textbook for JS one, (UBE Edition) which was recommended and used in all the school. The content materials were given to all the students during the lesson. Advanced organizers were given to students in the experimental group before the lesson; the 
Atomatofa, R.

control group will not be given organizers but only text materials during the lesson. The TCG consist of 30 questions carefully drawn from past junior secondary certificate examinations of the state. The researcher ensured the questions covered the concepts: gravitation and weightlessness, space travel and satellites, using a specification adopted from Bloom's taxonomy of educational objective. The TCG used as pretest, post-test and retention test was the same but scrambled. The students were not pre-informed about the delayed retention test taken 2 weeks after post-test.

\subsection{Validity of instruments}

The three instruments (teaching guides for topics, organizers and the Test of gravity concept TCG) were subjected to face validities by experts in the field of curriculum and integrated-science. The content validity of the Basic science concept attainment test was established using the table of specification adopted from Bloom taxonomy of educational objectives. The experts ensured the questions were well distributed and conformed strictly to the specifications. They assessed time, language level, clarity and relevance of each test item to the learning content material. Based on their decisions some item were deleted or retained. The advanced-organizers and test of gravity are seen in the appendix session.

\subsection{Reliability of instruments}

The reliability of the instrument was established by conducting a pilot test on 40 students from a school different from the schools used for the study that had similarity with the ones used for the work. Using the Kuder-Richardson formula, a Co-efficient of 0.62 was established. See appendix for the reliability test scores.

\subsection{Data collection}

The administration of research instrument took place in the two schools used for the study. The advanced organizers meant for each lesson were given to only the experimental group a day before each lesson. The lessons were taught to both groups and text materials given to all the students. The pretest, posttest and delayed retention tests as well as the treatments sessions were administered by research assistants specially trained by the researcher for each of the two groups. The trained research assistants were clearly told the objectives of the exercise to avoid bias. The entire tests administered were collected and given to the researcher on the agreed day for data analysis.

\subsection{Method of data analysis}

Responses from all the treatment groups were pooled together to give a total of two groups (experimental and control). Descriptive statistics were done to find out differences in the pretest, posttest and retention test means of subjects in all the groups which gave answers to the research questions. The t-test statistic was used to show if there were cases of significant differences in hypotheses one and two.

\section{Results}

Below is a presentation of the results of findings in this study. The results shows both the descriptive statistics that determined the answers to the research questions as well as the inferential statistics that gave room for testing of the various hypotheses:

\section{Table 2}

Pretest, Posttest and Retention Descriptive Data for both Groups

\begin{tabular}{llllll}
\hline Groups & Delayed retention means & Post-test mean & Pre-test mean & Tests difference & Retention difference \\
\hline Advanced organizer group & 17.58 & 16.00 & 8.43 & 7.57 & 1.58 \\
No-organizer group & 12.80 & 14.33 & 8.20 & 6.13 & -1.53 \\
\hline
\end{tabular}


The table shows that there are differences in posttest and pretest means of the subjects in both groups with the advanced organizer group having the higher means in pretest, posttest and retention test. The pretest scores of subjects in the two groups were 8.20 for the No-organizer group and 8.45 for the advanced organizer group. The advanced organizer group had the higher mean difference of posttest and pretest (7.57); and also had the higher mean difference in retention and posttest (1.58).

\subsection{Research question 1}

Will there be any difference in the attainment of the concept of gravity among subjects exposed to advance-organizers and those not exposed to organizers? From the table one above, it is seen that there are differences of posttest means in attainment of the concept of gravity among subjects exposed to advanced-organizers and No-organizer with posttest means of 16.00 and 14.33 respectively. The advanced-organizer group had the higher mean while the No-organizer group had the lower mean.

\subsection{Research question 2}

Will there be any difference in the delayed retention of the concept of gravity among subjects exposed to Advanced-organizers and those not exposed to organizers? Data in table one reveals that there are differences of delayed retention among subjects exposed to advanced-organizers and No-organizer with the advanced organizer group having the higher mean (17.58), while the No-organizer had the lower mean (12.80). Analysis of hypotheses one to three using the t-test as seen in the table below will show if the differences between the groups in terms of attainment and retention of the concepts of gravity are significant or not.

\section{Table 3}

Showing the t-test analysis of subjects in any two groups.

\begin{tabular}{cllllllll}
\hline Groups & & $\mathrm{N}$ & $X$ & $S D$ & $d f$ & $\mathrm{t}$-cal & t-table & remarks \\
\hline \multirow{2}{*}{ (Ho1) } & AO & 40 & 16.00 & 3.79 & 78 & 2.11 & 1.96 & Significant \\
& NO & 40 & 14.33 & 3.27 & & & & Reject Ho1 \\
& AOR & 40 & 17.58 & 2.69 & 78 & 7.30 & 1.96 & Significant \\
& NOR & 40 & 12.80 & 3.15 & & & & Reject Ho2 \\
\hline
\end{tabular}

Note. (AO \& NO -Advanced \& No-organizer groups in concept attainment test; AOR \& NOR - Advanced and No- Organizer groups in Retention test)

\subsection{Hypothesis testing 1}

There is no significant difference in the attainment of the concept of gravity between subjects exposed to Advance-organizers and those not exposed to Organizers. From table above, the t-test calculated values for the attainment of the concepts of gravity between the advanced-organizer (AO) group and the No-organizer (NO) group gave a value of 2.11 which is greater than the t-table value of 1.96. Thus the Hypothesis one is rejected meaning there is a significant difference in attainment of the concepts of gravity between subjects exposed to advanced-organizers and those not exposed to organizers with the organizer group performing better than the No-organizer group.

\subsection{Hypothesis testing 2}

There is no significant difference in the delayed retention of the concept of gravity between subjects exposed to advanced-organizers and those not exposed to Organizers. From table above, the t-table value is 1.96 while the $t$-calculated values for the delayed retention of concept of gravity between subjects exposed to advanced organizers and those not exposed to organizers is 7.30. This value is greater than the table value and therefore shows that there is a significant difference between subjects in the two groups in terms of retention with the advanced organizer group with a mean of 17.58 performing better than those in the control group with a mean of 
12.80. This means rejection of the hypothesis two meaning there is a significant difference in the delayed retention of the concept of gravity between subjects exposed to advanced organizers and those not exposed to advanced organizer with the advanced organizer group performing better.

\section{Discussions}

The purpose of this research was to find out if the students taught lessons on gravitation, weightlessness and space travels did better when given organizers before the lesson than their counterparts not given any organizers in both attainment and retention test. It also found out if those given advanced organizers did better than those not given organizers in both attainment and delayed retention of the concepts taught. Results of this study agree with studies carried out by Seweje (1987), Mohammed (1991), Akinyemi (1992), Ajaja (2006), and Ojeifo (2000). In the separate studies carried out by these researchers they found out that the use of advanced organizers by students had facilitating effects on the students learning and retention of the concepts they were taught. The students learning were thereby enhanced. Seweje (1987) and Mohammed (1991) found out that the students in different classes performed better with the use of organizers in addition to the lessons.

\section{Conclusion}

In conclusion the researcher recommends that students should be given advanced-organizers in addition to good instructional methods and texts. Advanced organizers should be given before the lessons to the students by the teachers since these are found to often have at least small facilitative effects for learners in most learning situations especially when it involves entire new learning. Also recommended is that, the government and those in educational affairs should encourage teachers who teach science concepts by providing them with materials or items that can serve as advanced organizers for students to learn science concepts better. When advanced organizers are used the students attain and retain science concepts better.

\subsection{Educational implications for the study}

Several educational researches have been carried out by science educators on how science students especially in the junior secondary levels can achieve better in science subjects. The search for better teaching methods led to this study on the use of advanced organizers to teach students the scientific concepts they have not been taught before. The topics gravitation and weightlessness are usually first introduced to junior secondary one students for the first time in the basic science curriculum. Therefore this study shows that the students who were taught with advanced organizers prior to the lesson did better than those who were just taught without the introduction of advanced organizers. Thus this study has provided some useful empirical evidence for the teaching and learning of the topics gravitation and weightlessness using advanced organizers for improved understanding and retention of the scientific concepts. Teachers who teach basic science formally known as integrated science should be encouraged to use advanced organizers to teach students topics they have not been taught before. The Educational planners and Curriculum planners should make efforts to give teachers assistance to get materials needed for advanced organizers. The teachers should also be trained on how to improvise and prepared relevant advanced-organizers for their science lessons as this study shows that they can improve attainment and retention of newly introduced concepts in science.

\section{References:}

Adejumo, J. A. (1972). Use of guide questions as post organizers in verbal learning: A retrieval mechanism. West African Journal of Education, 16(3), 285-291.

Ajaja, P. O. (2006). A comparison of retention outcome of advanced organizer, discovery and invention methods of teaching biology in Nigerian secondary schools. The Nigerian Journal of Education, 4(2), 229-240.

Akeju, O. A. (2001). Relative effectiveness of teacher demonstration and structural inquiry and gender on subjects learning outcomes in chemistry practicals. University of Ibadan Education and Information 
Effects of advanced organizers on attainment and retention of students' concept of gravity in Nigeria

Studies Abstract, 2000-2002.

Akinyemi, A. (1992). The effect of pre-instructional strategies on the acquisition and retention of pose material. Illorin Journal of Education, 12(1), 129-135.

Allen, D. I. (1970). Some effects of advance organizers and level of question on the learning and retention of written social studies materials. Journal of Educational Psychology, 61(5), 333-339. http://dx.doi.org/10.1037/h0029909

Atomatofa, R. (2007). Relative effects of inquiry, discussion and lecture methods of teaching integrated-science on students' achievements. Unpublished masteral thesis, Delta State University, Abraka, Nigeria.

Ausubel, D. (1968). Educational psychology. A cognitive view. New York: Rinehart and Winston Inc.

Ausubel, D. P. (1978). In defense of advance organizers. A reply to critics. Review of Educational research 48(2), 251-257.

Egbugara, U. (1983). Effects of three levels of an advance organizer and achievement of some Nigerian secondary school physics students. Unpublished doctoral thesis, university of Ibadan.

Erylimaz, A.,Yilmaz, S., \& Yilimaz, M. (2000). Analogies on students' misconceptions about gravity and inertia. Retrieved from http://www.efdergi.hacetep.edu.tr/engish/htm

Ibegbulam, C. (1980). Effects of orienting stimuli on the attitudes and achievements in biology of a group of Nigerian secondary school pupils. Unpublished doctoral thesis, University of Ibadan.

Kayode, A .O. (1997). The Nigerian teacher education curriculum and the issue of relevance to national development. Teacher Education Review, 1, 111-119.

Keraro, F. N., \& Shihusa, H. (2009). Using advance organizers to enhance students motivation in biology Eurasia Journal of Maths, Science and Technology Education, 5(4), 413-420.

Kirkam, G., \& Shaw E. L (1997). Effects of an oral advance organizer on immediate and delayed retention. Paper presented at the $26^{\text {th }}$ Annual meeting at Mid-South Education Research Association, Memphis.

Kulkowich, J. M., \& Schulz, S. K. (1994). Cues, questions, and advance organizers. Retrieved from http://www.netc.pp/focusstrategies/andphp

Laoye, O. (1992). Differential effects of the use of linguistic approach and advance organizers on the performance of SS1 students in Geometry. Unpublished doctoral dissertation. University of Ibadan.

Lin, H., \& Chen, T. (2006). Decreasing cognitive load for novice EFL learners: Effects of question and descriptive advance organizers in facilitating EFL learners' comprehension of an animation-based content lesson. System: An International Journal of Educational Technology and Applied Linguistics, 34(3), 416-431. http://dx.doi.org/10.1016/j.system.2006.04.008

Lin, H., Kidwai, K., Swain, J., Ausman, B., \& Dwyer, F. (2005). The Effect of verbal advance organizers in complementing animated instruction. Journal of Visual Literacy, 25(2), 237 - 248.

Mayer, R. E. (1979). Can advance organizers influence meaningful learning? Review of Educational Research, 4(2), 371-383.

Mazano, R., Pickering D. J., \& Pollock, J. E. (2001). Strategies for increasing student achievement from classroom instruction: Research-based strategies. Alexandria, VA: Association for Supervision and Curriculum Development.

Mohammed, A. (1991).Some Mathemagenic activities and the learning of some social studies concepts by secondary school pupils in Sokoto state. Unpublished doctoral dissertation, University of Ibadan.

NERDC. (2006). 9 year basic education curriculum for junior secondary 1-3. Nigeria: NERDC.

Nneji, N. G. (1997). Understanding teaching and evaluation skill acquisition. Teacher Education Review, 1, $47-51$.

Ojeifo, J. A. (2000). Effects of advance and post organizers on concept attainment of junior secondary school students in social studies. Unpublished doctoral dissertation, Delta state University, Abraka.

Ojerinde, D. (1986). Ought Mathematical vocabularies be taught before mathematics? An Experimental Verification. Empirical Studies of Curriculum Issues in Nigeria, 4, 151-164.

Redfeld, D. L., \& Rousseau, E. W. (1981). A Meta-analysis of experimental research on teacher questioning behaivour. Review of Educational Research, 51(2), 237-245.

Risner, G. P., Nicholson, J. I., \& Webb, B. (1994). Levels of comprehension promoted by the Cooperative 
Atomatofa, R.

Integrated Reading and Composition (CIRC) Program. Florence: University of North Alabama. (ERIC Document Reproduction Service No. ED 381751 )

Salmon, M. F. (2000). Effects of pre-instructional strategies on teaching and learning of selected mathematical concepts at senior secondary school level. Illorin Journal of Education, 12(1), 136-142.

Seweje, R. O. (1987). Effects of differentially structured advance organizers

Umudhe, S. E. (1998). Science teaching methods in Nigeria. In P. O. Itedjere (Ed.) Current issues in Nigerian educational system. Benin. Osasu Publishers.

Woolfolk, A., Winne, P. H., Perry, N. E, \& Shapka, J. (2010). Educational psychology. Canada: Pearson Publishers.

Yewande, R. O. (2000). The effect of problem solving technique on students' achievement in chemistry. University of Ibadan Education and Information Studies Abstract 2000-2004. 